\title{
Diesel exhaust exposure enhances the ozone-induced airway inflammation in healthy humans
}

\author{
J. Bosson, S. Barath, J. Pourazar, A.F. Behndig, T. Sandström, \\ A. Blomberg and E. Ädelroth
}

ABSTRACT: Exposure to particulate matter and ozone cause adverse airway reactions. Individual pollutant effects are often addressed separately, despite coexisting in ambient air. The present investigation was performed to study the effects of sequential exposures to diesel exhaust (DE) and ozone on airway inflammation in human subjects.

Healthy subjects underwent bronchoscopy with bronchoalveolar lavage (BAL) and bronchial wash (BW) sampling on two occasions. Once following a DE exposure (with $300 \mu \mathrm{g} \cdot \mathrm{m}^{-3}$ particles with a $50 \%$ cut-off aerodynamic diameter of $10 \mu \mathrm{m})$ with subsequent exposure to $\mathrm{O}_{3}(0.2 \mathrm{ppm}) 5 \mathrm{~h}$ later. The other bronchoscopy was performed after a filtered air exposure followed by an ozone exposure, using an identical protocol. Bronchoscopy was performed $24 \mathrm{~h}$ after the start of the initial exposure.

Significant increases in neutrophil and macrophage numbers were found in BW after DE followed by ozone exposure versus air followed by ozone exposure. DE pre-exposure also raised eosinophil protein $X$ levels in BAL compared with air.

The present study indicates additive effects of diesel exhaust on the ozone-induced airway inflammation. Together with similar results from a recent study with sequential diesel exhaust and ozone exposures, the present data stress a need to consider the interaction and cumulative effects of different air pollutants.

KEYWORDS: Air pollution, bronchoscopy, neutrophils, particulate matter, sequential exposure

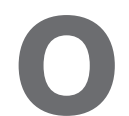

zone and particulate matter (PM) pollution have been linked with adverse effects on respiratory health in a large number of epidemiological studies. Both have been strongly associated with increased symptoms, reduced lung function, enhanced airway responsiveness, deterioration of asthma and chronic obstructive pulmonary disease, as well as increased healthcare visits and hospitalisation [1-5].

Diesel exhaust (DE) is an important source of PM pollution and reaches its peak concentrations during rush hour traffic. Ozone is a secondary pollutant to which nitrogen oxides $\left(\mathrm{NO}_{\mathrm{x}}\right)$, volatile organic compounds and sunlight contribute, thus causing ozone levels to commonly culminate in the afternoon. Both experimental and epidemiological studies have mainly focused on the separate effects of these air pollutants, although exposure to both occurs during the course of the day. However, in epidemiological studies it has often been difficult to distinguish the potentially additive health effects that a combination of PM and ozone exposure may generate. Experimental studies have the benefit that studies can be designed to delineate additive and modulating effects by one air pollutant upon the other.

Ozone is a powerful oxidant earlier demonstrated to cause oxidative stress in the human respiratory tract, resulting in an airway inflammatory response with neutrophilic inflammation reflected in the bronchial mucosa as well as in airway lavage fluids. Exposure to higher concentrations of ozone has been associated with substantial inflammatory effects as reflected in bronchoalveolar lavage fluid with increases in interleukin (IL)-6, IL-8, granulocyte-macrophage colony-stimulating factor and prostaglandin $E_{2}$ [6-8]. The time course of the airway mucosal inflammatory event has been determined in a preceding series of studies at 1.5, 6 and $18 \mathrm{~h}$ after ozone exposure [9-12].

Controlled DE exposure in human subjects has been shown to cause an inflammatory airway response with infiltration by neutrophils and
AFFILIATION

Dept of Respiratory Medicine and Allergy, University Hospital, Umeå Sweden.

\section{CORRESPONDENCE}

J. Bosson

Dept of Respiratory Medicine and Allergy

University Hospital

SE-901 85 Umeå

Sweden

Fax: 4690141369

E-mail: jenny.bosson@gmail.com

Received:

June 272007

Accepted after revision:

February 152008

SUPPORT STATEMENT

This study was funded by The Swedish Heart-Lung Foundation, Umeå University, The Swedish

Emission Research Programme, The Swedish Medical Research Council and The Swedish Research Council for Environment, Agricultural Sciences and Spatial Planning (all Stockholm, Sweden).

\section{STATEMENT OF INTEREST}

None declared. 
other cell types, as reflected in the bronchial mucosa as well as in bronchial wash (BW) $[13,14]$. A pronounced bronchial epithelial activation has been shown to be present, including increased signal transduction and cytokine production $[15,16]$. The time-course of these reactive events has previously been determined at 6 and $18 \mathrm{~h}$ after exposure with bronchoalveolar lavage (BAL) neutrophilia and alveolar macrophage increase persistent at the later time-point [13, 14, 17].

In a recent study, Bosson et al. [18] assessed whether an ozone exposure given after a DE exposure would enhance the dieselinduced airway inflammation, as compared with a subsequent air exposure. Ozone was found to cause a significant increase in the DE-induced sputum neutrophilia and the secretion of the potent oxidative enzyme myeloperoxidase (MPO) in healthy human subjects. Furthermore, strong correlations were found between MPO, matrix metalloproteinase(MMP)-9 and neutrophil numbers, implying a state of enhanced neutrophil activation by the addition of an ozone exposure to a preceding DE exposure. Consequently, these results suggest that ozone has the ability to magnify the established DE-induced airway inflammation.

The present study, in which the sequence of the filtered air exposure is reversed, was performed as a complement to the study of Bosson et al. [18] to further clarify the association of the airway inflammatory reactions in response to DE and ozone. The hypothesis was that pre-exposure to DE would enhance the ozone-induced airway inflammation in human subjects, with an increase in BW neutrophils being the primary end-point as based on a previous set of studies [9, $10,12,14-17]$.

\section{METHODS}

\section{Subjects}

A total of 14 healthy, nonsmoking subjects (five female and nine male; mean (range) age 25 (21-29) yrs) were recruited to the study. None had a history of asthma, allergies or other significant illness and all were free from airway infections for a minimum of 6 weeks prior to and during the study. All subjects had negative skin prick tests against common aeroallergens, and normal spirometry and ECG. The use of vitamins and nonsteroid anti-inflammatory drugs was not permitted for 2 weeks prior to exposure and extending until after the last bronchoscopy was performed. The study was approved by the Umeå University Ethics Committee (Umeå, Sweden) and all subjects had given their written informed consent. All research carried out was in compliance with the Helsinki Declaration.

\section{Study design}

Bronchoscopy with BW and BAL was performed on two occasions. Once following a 1-h morning DE exposure with subsequent 2-h exposure to ozone, $5 \mathrm{~h}$ later. The second bronchoscopy was carried out after a filtered air morning exposure followed by an ozone exposure, using an identical time-frame as before. The two exposure series were randomised and a double-blinded approach was employed. Both bronchoscopies were performed $24 \mathrm{~h}$ after the start of the initial exposure (i.e. $16 \mathrm{~h}$ after the end of the ozone exposure; fig. 1). A minimum of 3 weeks and a maximum of 5 weeks separated the two exposure series. During all exposures, subjects alternated between rest and moderate exercise on a stationary bicycle ergometer (with minute ventilation $\left(V^{\prime} \mathrm{E}\right)=20 \mathrm{~L} \cdot \mathrm{min}^{-1} \cdot \mathrm{m}^{-2}$ body surface) at 15 -min intervals.

\section{Exposures}

The exposures were carried out in two separate 'walk-in' chambers, one for ozone and one for DE. Ozone was generated using a Fischer's $\mathrm{O}_{3}$ generator $500 \mathrm{MM}$ (Fischer Labor and Verfahrens-Technik, Bonn, Germany) and a concentration of $0.2 \mathrm{ppm}$ was continuously monitored and maintained in the chamber [9]. DE at a steady state concentration of $300 \mu \mathrm{g} \cdot \mathrm{m}^{-3}$ was generated by an idling Volvo diesel engine (Volvo TD45, 4.5L, 4 cylinders, 1991, $68 \mathrm{rpm}$ ). Particles with a 50\% cut-off aerodynamic diameter of $10 \mu \mathrm{m}$ concentration were measured with a gravimetric method as well as with a tapered element oscillating microbalance instrument, whereas $\mathrm{NOx}\left(\mathrm{NO}, \mathrm{NO}_{2}\right)$ and total hydrocarbons were monitored using on-line equipment $[14,19]$. The mean levels of gaseous pollutants during DE exposures for $\mathrm{NO}_{2}, \mathrm{NO}$ and total hydrocarbons were $0.51,1.65$ and 1.18 ppm, respectively.

\section{Bronchoscopy and processing of samples}

The subjects received atropine subcutaneously as pre-medication. Lidocaine was used for topical anaesthesia. The flexible video bronchoscope (BF1T160; Olympus, Tokyo, Japan) was introduced through the mouth with the subject in the supine position. BW was performed by an instillation of $2 \times 20 \mathrm{~mL}$ sterile saline solution ( $\mathrm{pH} 5.4$ at $37^{\circ} \mathrm{C}$ ), followed by BAL with $3 \times 60 \mathrm{~mL}$ saline solution, within the middle or lingula lobes, randomly selected for the two instances. The recovered aspirate from the first and second $20 \mathrm{~mL}$ instillations of BW and the collective BAL fluid were accumulated into individual containers and immediately placed on ice.

BW and BAL samples were used for total and differential cell counts as well as examination of soluble mediators. Lavage fluid was filtered to eliminate mucus (pore diameter $100 \mathrm{~mm}$; Syntab Product Ab, Malmö, Sweden) and centrifuged at $400 \times g$ for $15 \mathrm{~min}$ in order to separate cellular components from supernatant, which was then divided into aliquots and stored at $-80^{\circ} \mathrm{C}$ until analysis.

\section{Total and differential cell counts}

The cell pellets resulting from the BW and BAL fluid samples were resuspended in saline to a final concentration of $10^{6}$ cells $\cdot \mathrm{mL}^{-1}$ and used for total and differential cell counts. A Bürker chamber was used to determine total leukocyte

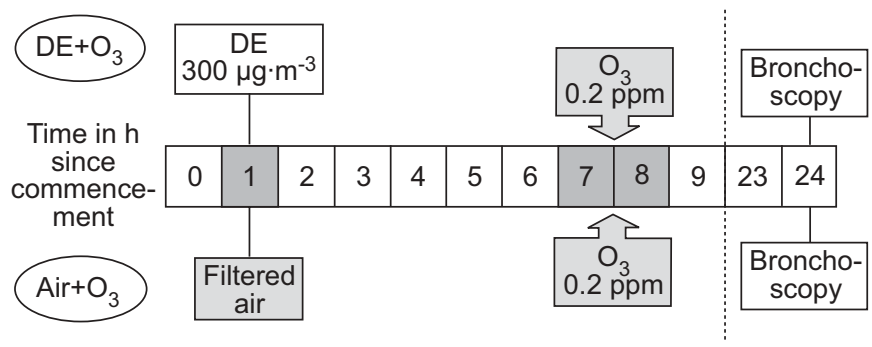

FIGURE 1. Schematic diagram of study design showing the timeline of the two randomised exposure sequences, diesel exposure $(\mathrm{DE})$ followed by ozone $\left(\mathrm{O}_{3}\right)$ and filtered air followed by $\mathrm{O}_{3}$, which all subjects completed on two separate occasions. 
numbers. A Cytospin 3 (Shandon Southern Instruments Inc., Sewikly, PA, USA) at $96 \times g$ for $5 \mathrm{~min}$ produced cytocentrifuged specimens, resulting in $5 \times 10^{4}$ nonepithelial cells per slide. Differential cell counts were carried out on slides stained with May-Grünwald Giemsa. On each slide, a total of 400 cells were counted.

\section{Soluble proteins and cytokines}

The lavage fluid supernatant was analysed using radioimmunoassay or ELISA for soluble inflammatory markers and cytokines, including IL-6 (monoclonal antibodies supplied by R\&D Systems Inc., Abingdon, UK), IL-8 (R\&D Systems Inc.), soluble intercellular adhesion molecule (sICAM; R\&D Systems Inc.), human neutrophil lipocalin (HNL; Dept of Clinical Chemistry, Uppsala, Sweden), eosinophil protein X (EPX; Diagnostics Development, Uppsala, Sweden), MPO (OXIS Research, CA, USA), and MMP-9 (R\&D Systems Inc.). HNL and EPX were analysed using previously described methods [20, 21]. Albumin was measured using a commercially available kit (Boehringer Mannheim, Mannheim, Germany).

These cytokines were chosen since they each indicate important pro-inflammatory signals. The soluble proteins were selected to demonstrate degree of neutrophil and eosinophil activation.

\section{Statistical analyses}

When comparing the cell count and soluble protein data of filtered air followed by ozone versus DE followed by ozone, Wilcoxon's nonparametric signed-rank test for paired observations was applied. Correlations were assessed using the Spearman correlation test. A p-value $<0.05$ was considered to be significant. Values are presented as medians with interquartile ranges (IQRs).

\section{RESULTS}

The median (IQR) BW recoveries after the exposure series were 5.8 (5.5-6.7) $\mathrm{mL}$ and $6.7(5.6-7.0) \mathrm{mL}$, after DE followed by ozone and filtered air followed by ozone, respectively. Corresponding BAL fluid recoveries were 128 (115-132) mL and 131 (118-144) mL. There was no significant difference between any of these recoveries.

\section{Inflammatory cell responses}

Exposure to DE significantly enhanced ozone-induced airway inflammation reflected in BW, as opposed to filtered air. Preexposure to DE generated significantly higher numbers of neutrophils $(p=0.006)$ and macrophages $(p=0.046)$. Eosinophils showed a clear tendency to increase, that did not reach statistical significance $(p=0.050$; table 1$)$. No significant differences were seen in other cell types in BW or in BAL (tables 1 and 2, respectively).

\section{Soluble protein and cytokine responses}

Pre-exposure with DE significantly increased the median (IQR) concentration of EPX in BAL fluid after ozone exposure, as opposed to pre-exposure to air $(0.25(0.00-0.49)$ and $0.41(0.00-$ $0.85)$ cells $\cdot L^{-1}$, respectively; $\left.p=0.04\right)$. No significant differences were found either in the collected BW or BAL regarding IL-6, IL-8, sICAM, HNL, MMP-9, MPO or albumin concentration (table 3).

\section{Correlations}

The total number of eosinophils in BAL was significantly correlated with the EPX concentration found in BAL after the $\mathrm{DE}$ and ozone challenge $\left(\mathrm{r}_{\mathrm{s}}=0.655 ; \mathrm{p}=0.011\right)$. There was also a trend towards significance seen between the percentage of eosinophils and EPX concentration in BAL following the same exposure series $\left(r_{\mathrm{s}}=0.515 ; \mathrm{p}=0.059\right)$.

\section{DISCUSSION}

The objective of the present study was to further increase the understanding of the inflammatory airway effects of sequential exposure to air pollutants, with an attempt to mimic real life. It was found that pre-exposure to DE enhances the ozoneinduced inflammation with significant increases in neutrophils and macrophages in the BW as well as an increase in EPX in BAL fluid, as compared with pre-treatment with air. These effects were demonstrated on top of the established ozoneinduced airway inflammation, thus signifying an inflammatory amplification by the preceding exposure to DE. Hence, the

\begin{tabular}{|c|c|c|c|}
\hline \multicolumn{4}{|l|}{ Macrophages } \\
\hline$\times 10^{4}$ cells $\cdot L^{-1}$ & $7.1(4.0-9.5)$ & $8.2(4.2-10.9)$ & 0.046 \\
\hline$\%$ & $57.3(44.5-64.5)$ & $56.0(37.0-65.8)$ & $0.245^{\circ}$ \\
\hline$\times 10^{4}$ cells $\cdot L^{-1}$ & $3.6(2.8-5.1)$ & $5.4(4.5-10.1)$ & 0.006 \\
\hline$\%$ & $36.8(24.1-51.0)$ & $39.0(29.0-58.0)$ & $0.209^{\circ}$ \\
\hline \multicolumn{4}{|l|}{ Lymphocytes } \\
\hline$\times 10^{4}$ cells $\cdot L^{-1}$ & $0.5(0.3-0.7)$ & $0.7(0.4-0.9)$ & $0.13^{\circ}$ \\
\hline$\%$ & $4.0(2.7-5.2)$ & $4.6(2.6-5.2)$ & $0.900^{\circ}$ \\
\hline \multicolumn{4}{|l|}{ Eosinophils } \\
\hline
\end{tabular}

Data are presented as median (interquartile range), unless otherwise stated. ${ }^{*}$ : calculated using Wilcoxon's signed rank test; ${ }^{\bullet}$ : nonsignificant. 
TABLE 2 Cells in bronchoalveolar lavage

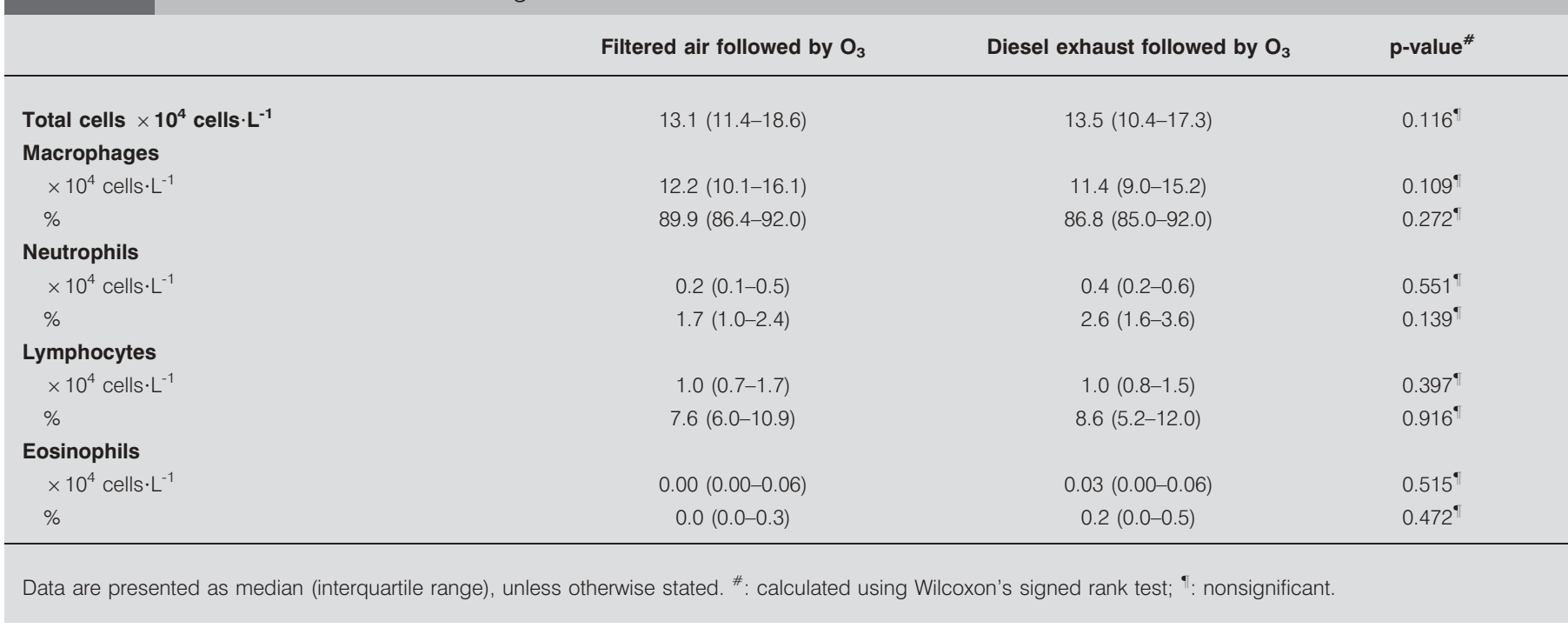

present findings suggest a need to consider additive effects of sequential or combined exposures, when it comes to regulation of exposure limits.

The present study was performed as a complement to a previous study which addressed whether a subsequent exposure to ozone, as compared with filtered air, would enhance the established DE-induced airway inflammation [18]. In the present study, the filtered air sequence was reversed to focus instead on whether a pre-exposure to DE would influence airway inflammation induced by ozone exposure, thereby providing additional information towards understanding the complex nature of sequential air-pollutant effects. Furthermore, the inflammatory responses in the airways to separate DE and ozone exposures have already been determined.

When considering the study design, ideally two additional series would have been included in terms of air followed by air as well as DE followed by air. Performing three or four exposure series in human volunteers, each with two sequential chamber exposures would not have been possible due to the complexity for research subjects, staff, resources and number of repeat bronchoscopies. Therefore, the present study has relied upon historical controls regarding the DE effects at 18$24 \mathrm{~h}$ in comparison with filtered air [13, 17]. Additionally, previous studies have determined the DE-induced inflammation in the bronchial mucosa as well as in the lavage fluids at $6 \mathrm{~h}$. This time point coincides which the ozone exposure in the present study and it should be taken into account that a DEinduced airway inflammation was established when the ozone challenge was given [14-16]. In addition, the effects of ozone exposure around the $16 \mathrm{~h}$ time-point, when bronchoscopies were performed in the present study, have previously been determined [9-12].

Both DE and ozone have the ability to induce oxidative stress in the airways [17, 22]. An increased neutrophil accumulation in addition to the exogenous source of oxidative stress has the potential to cause additional cell damage within the airway tissues.
In the present study a significant elevation of BW neutrophils was demonstrated when an ozone exposure was preceded by a DE exposure, as compared with pre-treatment with filtered air. This effect was seen on top of the ozone induced BW neutrophilia, which would have been present in both exposure series of the study, at the time of the bronchoscopy sampling, as shown in a previous study [12]. In the previous study, BW neutrophils were more than doubled and increased in median from 0.9 to $2.1 \times 10^{4}$ cells $\cdot \mathrm{mL}^{-1}$. To the best of the present authors' knowledge, all other studies addressing BW neutrophilia at $18 \mathrm{~h}$ post-exposure have employed higher doses of ozone and slightly different bronchoscopy methodology [23-25]. However, at these higher ozone (approximately three times) doses, the BW neutrophils were in the region of $6 \times 10^{4}$ cells $\cdot \mathrm{mL}^{-1}$. Accounting for discrepancies in methodology, doses and individual variation, the previous results are comparable with the findings after the filtered air followed by ozone exposure seen herein.

Several circumstances may have influenced the additive BW neutrophilia induced by $\mathrm{DE}$, demonstrated in the present study. It has previously been demonstrated that by $6 \mathrm{~h}, \mathrm{DE}$ challenge causes an activation of the bronchial epithelium by epidermal growth factor receptor (EGFR) with upregulation of phosphorylation of the specific EGFR tyrosine residue 1173, leading to activation of downstream p38, jun N-terminal kinase and mitogen-activated protein kinases controlling nuclear factor- $\kappa \mathrm{B}$ and activating protein-1 [16]. This in turn leads to the increase in the epithelial expression of the neutrophil chemoattractants IL- 8 and Gro- $\alpha$ as well as the vascular adhesion molecule expression of intercellular adhesion molecule-1 [15]. These data indicate that at the time-point for the ozone challenge, not only is an airway neutrophilia present but an underlying DE-induced epithelial activation also exists. This activation might be of consequence to the airway response when subsequently exposed to ozone.

The alveolar macrophage response at this late time-point (24 h) after DE challenge is similar to what has previously been reported $[17,19]$. Even though macrophages may potentially 


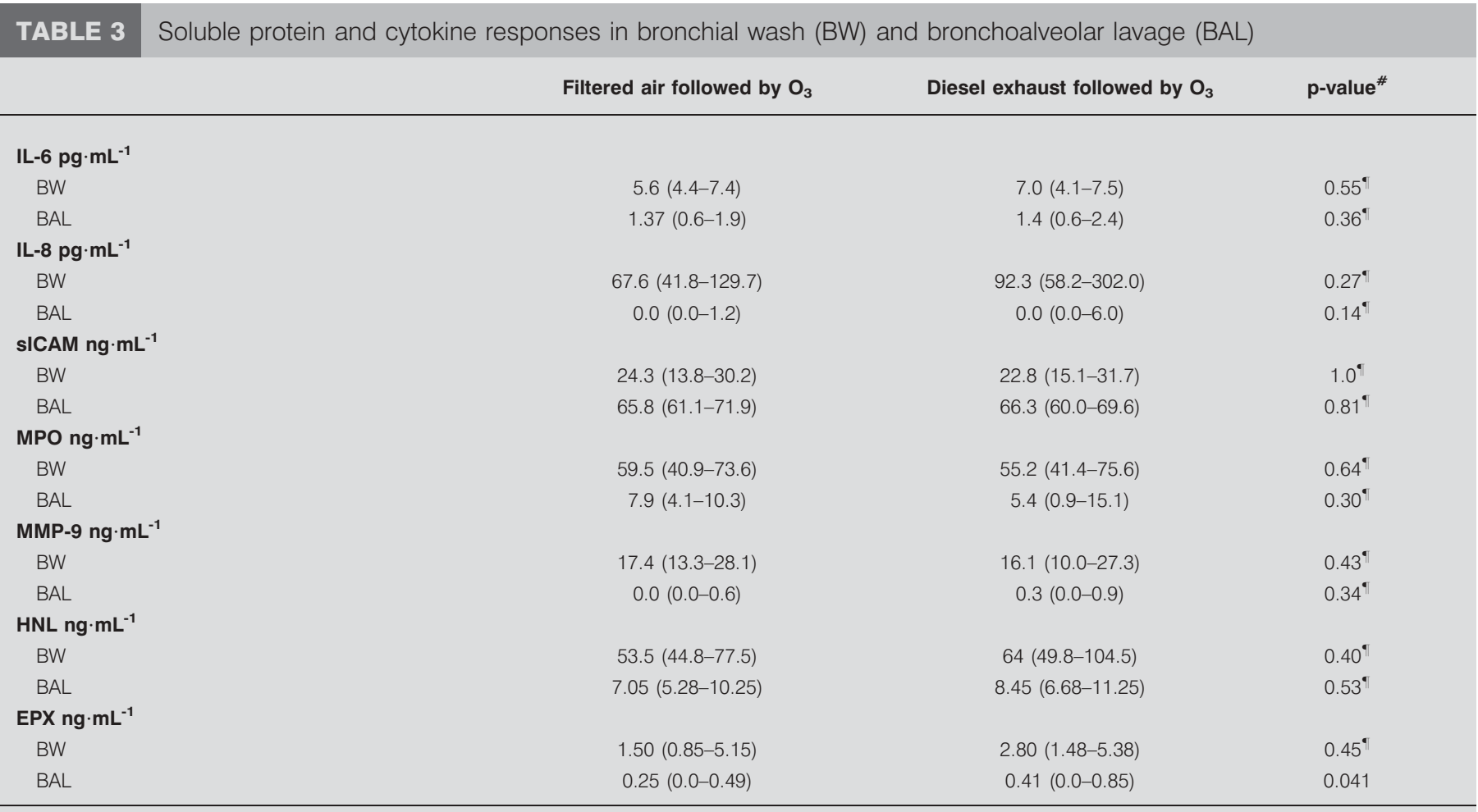

Data are presented as median (interquartile range), unless otherwise stated. IL: interleukin; sICAM: soluble intercellular adhesion molecule; MPO: myeloperoxidase; MMP: matrix metalloproteinase; HNL: human neutrophil lipocalin; EPX: eosinophil protein X. ${ }^{\#}$ : calculated using Wilcoxon's signed rank test; " : nonsignificant.

have regulatory properties through release of pro-inflammatory cytokines, the major recruitment of the cells occurs in this late phase to facilitate particle clearance $[17,19,26]$. The ingestion of diesel particles in vivo by alveolar macrophages has been determined to cause functional abnormalities with reduced phagocytosis, as shown in subsequent in vitro tests [19]. Furthermore, a diminished particle clearance has been reported as a consequence of particle-laden macrophages [27]. In epidemiological studies, these findings have been suggested to be associated with an increased risk of airway infections by PM air-pollution exposure. Two animal studies which have focused on the interaction of PM and ozone exposure support the demonstrated enhanced neutrophil and alveolar macrophage response in the airways after pre-treatment with DE followed by ozone (as compared with filtered air followed by ozone). Increased neutrophilia in rat airways was demonstrated after concomitant exposure to ozone and DE [28], as well as by ozone and ambient particulates fed through a particle concentrator [29]. ADAMSON et al. [29] were also able to demonstrate an increase of alveolar macrophage numbers caused by the combined exposure. To the best of the present authors' knowledge, there are no animal studies using a sequential exposure model of DE and ozone as in the present human study. The reason for the study design with sequential exposures was to investigate the potentially additive effects of DE and ozone. However, combining DE and ozone exposures in human subjects presents several problems. Extreme concentrations of ozone would have been required if it were to be mixed with the DE carried into the chamber. This is because the ozone would otherwise have been scavenged by the hydrocarbon content in the exhaust, leading to oxidisation and potential generation of altered chemical entities.

A significant increase in BAL EPX was found after preexposure with DE compared with filtered air. Since no accompanying significant rise in eosinophils was seen, this finding needs to be interpreted with caution. However, an increase in EPX indicates eosinophil activation, where granular contents of reactive proteins such as EPX, eosinophil cationic protein and eosinophil peroxidase would be released. These components have been linked with propagation and worsening of the asthmatic airway inflammation, as well as clinical deterioration and increased airway hyperresponsiveness [30]. Previous experimental studies have found a significant rise in eosinophils in induced sputum in healthy subjects at 1 and $24 \mathrm{~h}$ after a 0.25 ppm ozone exposure [31], whereas no ozone-induced eosinophilia has been reported in airway lavages in healthy subjects. Airway eosinophilia has not been previously discovered in healthy subjects in earlier DE exposure studies. This raises the question of whether the increased EPX level indicates a combination effect by the pollutants. If this eosinophil activation in fact is a consequence of a DE and ozone exposure combination in these healthy subjects, it could well be more pronounced in asthmatics exposed to a similar sequence of air pollutants. This could be of clinical importance, since airway eosinophilia and eosinophil activation is linked to hyperresponsiveness and exacerbations of asthma, and both DE and ozone have been implicated as causative agents [30, 32, 33]. 
Taken together, the human studies employing sequential exposures to DE and ozone suggest that an additional, rather than synergistic effect occurs in terms of airway inflammatory parameters attributable to the two pollutants. This is in accordance with epidemiological data implying a hazardous interaction between exposure to PM and ozone [34, 35].

The present study shows that when diesel exhaust exposure was administered before the ozone exposure, in order to mimic an ambient urban pollution profile, there was a significant increase in neutrophil and macrophage recruitment as well as increased release of eosinophil protein $\mathrm{X}$, indicating eosinophil activation. Together with similar results from a recent study with sequential diesel exhaust and ozone exposures, the present data further stress the need to consider both the interactive and cumulative effects of different air pollutants.

\section{ACKNOWLEDGEMENTS}

The authors would like to thank F. Holmström, A. Johansson, H. Bogseth, A-B. Lundström, M-C. Ledin (all Dept of Respiratory Medicine and Allergy, University Hospital, Umeå, Sweden), K. Linblad (Dept of Medical Biochemistry and Microbiology) and P. Venge (Dept of Clinical Chemistry and Pharmacology, University Hospital, Uppsala, Sweden) for their excellent technical assistance.

\section{REFERENCES}

1 Dockery DW, Pope CA 3rd, Xu X, et al. An association between air pollution and mortality in six U.S. cities. N Engl J Med 1993; 329: 1753-1759.

2 Brunekreef B, Holgate ST. Air pollution and health. Lancet 2002; 360: 1233-1242.

3 Gryparis A, Forsberg B, Katsouyanni K, et al. Acute effects of ozone on mortality from the "air pollution and health: a European approach" project. Am J Respir Crit Care Med 2004; 170: 1080-1087.

4 Atkinson RW, Anderson HR, Sunyer J, et al. Acute effects of particulate air pollution on respiratory admissions: results from APHEA 2 project. Air Pollution and Health: a European Approach. Am J Respir Crit Care Med 2001; 164: 1860-1866.

5 Medina-Ramón M, Zanobetti A, Schwartz J. The effect of ozone and PM10 on hospital admissions for pneumonia and chronic obstructive pulmonary disease: a national multicity study. Am J Epidemiol 2006; 163: 579-588.

6 Devlin RB, McDonnell WF, Mann R, et al. Exposure of humans to ambient levels of ozone for 6.6 hours causes cellular and biochemical changes in the lung. Am J Respir Cell Mol Biol 1991; 4: 72-81.

7 Koren HS, Devlin RB, Graham DE, et al. Ozone-induced inflammation in the lower airways of human subjects. $A m$ Rev Respir Dis 1989; 139: 407-415.

8 Balmes JR, Chen LL, Scannell C, et al. Ozone-induced decrements in FEV1 and FVC do not correlate with measures of inflammation. Am J Respir Crit Care Med 1996; 153: 904-909.

9 Blomberg A, Mudway IS, Nordenhäll C, et al. Ozoneinduced lung function decrements do not correlate with early airway inflammatory or antioxidant responses. Eur Respir J 1999; 13: 1418-1428.
10 Stenfors N, Pourazar J, Blomberg A, et al. Effect of ozone on bronchial mucosal inflammation in asthmatic and healthy subjects. Respir Med 2002; 96: 352-358.

11 Bosson J, Stenfors N, Bucht A, et al. Ozone-induced bronchial epithelial cytokine expression differs between healthy and asthmatic subjects. Clin Exp Allergy 2003; 33: 777-782.

12 Stenfors N. Differential airway inflammatory responses to ozone and diesel exhaust in healthy and asthmatic subjects. Medical Dissertation. Umeå University, Umeå, Sweden, 2002.

13 Rudell B, Blomberg A, Helleday R, et al. Bronchoalveolar inflammation after exposure to diesel exhaust: comparison between unfiltered and particle trap filtered exhaust. Occup Environ Med 1999; 56: 527-534.

14 Salvi S, Blomberg A, Rudell B, et al. Acute inflammatory responses in the airways and peripheral blood after shortterm exposure to diesel exhaust in healthy human volunteers. Am J Respir Crit Care Med 1999; 159: 702-709.

15 Salvi SS, Nordenhall C, Blomberg A, et al. Acute exposure to diesel exhaust increases IL- 8 and GRO- $\alpha$ production in healthy human airways. Am J Respir Crit Care Med 2000; 161: 550-557.

16 Pourazar J, Mudway IS, Samet JM, et al. Diesel exhaust activates redox-sensitive transcription factors and kinases in human airways. Am J Physiol Lung Cell Mol Physiol 2005; 289: L724-L730.

17 Behndig AF, Mudway IS, Brown JL, et al. Airway antioxidant and inflammatory responses to diesel exhaust exposure in healthy humans. Eur Respir J 2006; 27: 359-365.

18 Bosson J, Pourazar J, Forsberg B, Adelroth E, Sandström T, Blomberg A, Ozone enhances the airway inflammation initiated by diesel exhaust. Respir Med 2006; 101: 1140-1146.

19 Rudell B, Sandström T, Hammarström U, Ledin ML, Hörstedt P, Stjernberg N. Evaluation of an exposure setup for studying effects of diesel exhaust in humans. Int Arch Occup Environ Health 1994; 66: 77-83.

20 Peterson CG, Venge P. Purification and characterization of a new cationic protein-eosinophil protein-X (EPX)-from granules of human eosinophils. Immunology 1983; 50: 19-26.

21 Xu SY, Petersson CG, Carlson M, Venge P. The development of an assay for human neutrophil lipocalin (HNL)-to be used as a specific marker of neutrophil activity in vivo and vitro. J Immunol Methods 1994; 171: 245-252.

22 Mudway IS, Stenfors N, Blomberg A, et al. Differences in basal airway antioxidant concentrations are not predictive of individual responsiveness to ozone: a comparison of healthy and mild asthmatic subjects. Free Radic Biol Med 2001; 31: 962-974.

23 Mudway IS, Kelly FJ. An investigation of inhaled ozone dose and the magnitude of airway inflammation in healthy adults. Am J Respir Crit Care Med 2004; 169: 1089-1095.

24 Balmes JR, Aris RM, Chen LL, et al. Effects of ozone on normal and potentially sensitive human subjects. Part I: Airway inflammation and responsiveness to ozone in normal and asthmatic subjects. Res Rep Health Eff Inst 1997; 78: 1-37.

25 Frampton MW, Morrow PE, Torres A, et al. Effects of ozone on normal and potentially sensitive human subjects. Part II: Airway inflammation and responsiveness to ozone in nonsmokers and smokers. Res Rep Health Eff Inst 1997; 78: 39-72. 
26 Kafoury RM, Madden MC. Diesel exhaust particles induce the over expression of tumor necrosis factor- $\alpha$ (TNF- $\alpha$ ) gene in alveolar macrophages and failed to induce apoptosis through activation of nuclear factor- $\kappa \mathrm{B}$ (NFкB). Int J Environ Res Public Health 2005; 2: 107-113.

27 Sydbom A, Blomberg A, Parnia S, Stenfors N, Sandström T, Dahlen SE. Health effects of diesel exhaust emissions. Eur Respir J 2001; 17: 733-746.

28 Madden MC, Richards JH, Dailey LA, Hatch GE, Ghio AJ. Effect of ozone on diesel exhaust particle toxicity in rat lung. Toxicol Appl Pharmacol 2000; 168: 140-148.

29 Adamson IY, Vincent R, Bjarnason SG. Cell injury and interstitial inflammation in rat lung after inhalation of ozone and urban particulates. Am J Respir Cell Mol Biol 1999; 20: 1067-1072.

30 Lee SY, Kim HB, Kim JH, et al. Eosinophils play a major role in the severity of exercise-induced bronchoconstriction in children with asthma. Pediatr Pulmonol 2006; 41: 1161-1166.
31 Holz O, Jörres RA, Timm P, et al. Ozone-induced airway inflammatory changes differ between individuals and are reproducible. Am J Respir Crit Care Med 1999; 159: 776-784.

32 Nordenhäll C, Pourazar J, Ledin MC, Levin JO, Sandström T, Adelroth E. Diesel exhaust enhances airway responsiveness in asthmatic subjects. Eur Respir J 2001; 17: 909-915.

33 Peden DB, Boehlecke B, Horstman D, Devlin R. Prolonged acute exposure to $0.16 \mathrm{ppm}$ ozone induces eosinophilic airway inflammation in asthmatic subjects with allergies. J Allergy Clin Immunol 1997; 100: 802-808.

34 Hoek G, Brunekreef B, Verhoeff A, van Wijnen J, Fischer P. Daily mortality and air pollution in The Netherlands. J Air Waste Manag Assoc 2000; 50: 1380-1389.

35 Aga E, Samoli E, Touloumi G, et al. Short-term effects of ambient particles on mortality in the elderly: results from 28 cities in the APHEA2 project. Eur Respir J 2003; 21: Suppl. 40, 28s-33s. 